\title{
Effect of egg yolk powder on freezability of Murrah buffalo (Bubalus bubalis) semen
}

\author{
N. Kumar' ${ }^{1}$ S. A. Lone ${ }^{1}$, J. K. Prasad ${ }^{2}$, M. H. Jan ${ }^{3}$ and S. K. Ghosh ${ }^{2}$
}

1. Division of Animal Reproduction, Gynecology \& Obstetrics, NDRI, Karnal, Haryana, India; 2. Germ Plasm Centre, Division of Animal Reproduction, Indian Veterinary Research Institute, Izatnagar, Bareilly, Uttar Pradesh, India;

3. Central Institute for Research on Buffalo, Hisar, Haryana, India.

Corresponding author: N. Kumar, e-mail: drnishantvet@yahoo.com, SAL: drloneshabir@gmail.com, JKP: jkprasad2001@yahoo.com,MHJ: mhjanivri@gmail.com, SKG: skghoshivri@yahoo.com

Received: 05-02-2016, Accepted: 03-05-2016, Published online: 17-06-2016

doi: 10.14202/vetworld.2016.601-604 How to cite this article: Kumar N, Lone SA, Prasad JK, Jan MH, Ghosh SK (2016) Effect of egg yolk powder on freezability of Murrah buffalo (Bubalus bubalis) semen, Veterinary World, 9(6): 601-604.

\begin{abstract}
Aim: The aim of this study was to investigate the effect of commercial egg yolk powder as an alternative to fresh egg yolk on freezability of Murrah buffalo semen.

Materials and Methods: Semen samples (12) from 3 Murrah buffaloes (4 from each bull) with mass motility ( $\geq 3+$ ) and total motility ( $70 \%$ and above) were utilized in this study. Immediately after collection, each sample was divided into four groups. Groups I was diluted up to $60 \times 10^{6} \mathrm{sperm} / \mathrm{ml}$ with tris extender containing $10 \%$ fresh egg yolk and Groups II, III, and IV were diluted up to $60 \times 10^{6} \mathrm{sperm} / \mathrm{ml}$ with tris extender containing $2 \%, 4 \%$, and $6 \%$ egg yolk powder, respectively. Semen samples were processed and cryopreserved followed by examination of frozen semen samples after $24 \mathrm{~h}$. Semen samples from each group were evaluated for total motility, viability, acrosomal integrity, abnormality, and hypo-osmotic swelling test (HOST) response after dilution, pre-freeze, and post-thaw stage.
\end{abstract}

Results: Pre-freeze total motility was significantly $(\mathrm{p}<0.05)$ higher in Groups III and IV as compared to Groups I and II, and post-thaw total motility was significantly $(p<0.01)$ higher in Group III as compared to other three groups. Viability was significantly $(\mathrm{p}<0.05)$ higher in Groups II, III, and IV than Group I at the pre-freeze stage. Significantly $(\mathrm{p}<0.01)$ higher viability and acrosomal integrity were recorded in Group III as compared to other three groups at the post-thaw stage. Abnormality was significantly $(\mathrm{p}<0.05)$ higher in Group IV than other three groups. HOST response was significantly $(\mathrm{p}<0.05)$ higher in Groups II and III than Groups I and IV at the pre-freeze and post-thaw stages.

Conclusion: Addition of egg yolk powder at 4\% level yielded significantly better results in terms of post-thaw semen quality as compared to the fresh egg yolk and other concentrations of egg yolk powder ( $2 \%$ and $6 \%)$.

Keywords: buffalo semen, egg yolk powder, freezability.

\section{Introduction}

The beneficial effect of egg yolk on spermatozoa during liquid storage and cryopreservation was first time reported by Phillips and Lardy in 1940 [1]. Egg yolk protects spermatozoa against cold shock, reduces loss of acrosomal enzymes, and helps in preserving semen quality [2]. The protective effects of egg yolk are due to low-density lipoprotein fraction present in it. Egg yolk has been included in dilutor at concentrations ranging from $1.5 \%$ to $50 \%$ [2]. Harvesting egg yolk is a cumbersome process because it involves proper disease screening, disinfection, skilful breaking of the outer shell, and inner membrane to separate the yolk from albumin and chalazae [3].

Due to the animal origin of egg yolk, it represents a potential risk of microbial contamination in

Copyright: Kumar, et al. Open Access. This article is distributed under the terms of the Creative Commons Attribution 4.0 International License (http://creativecommons.org/licenses/by/4.0/), which permits unrestricted use, distribution, and reproduction in any medium, provided you give appropriate credit to the original author(s) and the source, provide a link to the Creative Commons license, and indicate if changes were made. The Creative Commons Public Domain Dedication waiver (http://creativecommons.org/ publicdomain/zero/1.0/) applies to the data made available in this article, unless otherwise stated. the diluent. Although egg yolk benefits spermatozoa during cryopreservation, it can represent a potential risk to cells as they may contain specific microbial agents or other contaminants that may compromise sperm quality [4]. Terrestrial Animal Health Code (OIE) recommended that products used to treat spermatozoa should originate from sources of animal origin, which are free from any health risks [5]. This can be accomplished using egg yolk powder, instead of fresh egg yolk, as it is pasteurized. The use of egg yolk powder is documented for the cryopreservation of ovine [6], Zebu bull [7], and buffalo [8] and it is reported that semen treated with egg yolk powder had higher post-thaw motility as compared to fresh egg yolk treated semen.

In buffalo semen, egg yolk powder was used at the rate of $5 \%, 10 \%$, and $20 \%$, and it was shown that at higher concentration of egg yolk powder $(20 \%)$, the post-thaw quality of semen deteriorated [8]. It is, therefore, hypothesized that the use of egg yolk powder in the dilutor for the cryopreservation of buffalo bull semen at lesser concentration as reported earlier will not compromise the post-thaw attributes, and the same will reduce the cost of cryopreservation. Hence, 
the present study was designed to investigate the effect of egg yolk powder on quality and freezability of buffalo semen.

\section{Materials and Methods \\ Ethical approval}

No ethical approval was necessary to pursue this research work.

\section{Experimental animals}

Three healthy breeding buffalo bulls of approximately 4-6 years of age maintained at GermPlasm Center of Animal Reproduction Division, IVRI, Izatnagar, were utilized for the study. These bulls were kept under identical feeding and managemental conditions during the entire course of theinvestigation.

\section{Collection of semen and its processing}

Four different dilutors containing $2 \%, 4 \%$, and $6 \% \mathrm{w} / \mathrm{v}$ egg yolk powder (Sigma, USA) and $10 \% \mathrm{v} / \mathrm{v}$ fresh egg yolk, respectively, were prepared and kept at $37^{\circ} \mathrm{C}$. A total of 12 ejaculates (4 from each bull) were collected from three Murrah breeding bulls with artificial vagina. Ejaculates with mass motility $\geq 3+$ and total motility $70 \%$ and above were utilized for the present study. Semen ejaculates that qualified for cryopreservation were split into four groups. Group I was diluted with tris-egg yolk-glycerol dilutor (containing $10 \%$ fresh egg yolk) up to $60 \times 10^{6}$ spermato$\mathrm{zoa} / \mathrm{ml}$. Groups II, III, and IV were diluted with tris dilutor containing $2 \%, 4 \%$, and $6 \%$ egg yolk powder, respectively. After dilution, the percentage of various seminal attributes (total motility, viability, acrosomal integrity, abnormality, and hypo-osmotic swelling response) was recorded in each group.

\section{Semen freezing and its evaluation}

French mini straws $(0.25 \mathrm{ml})$ were filled with the diluted semen samples, sealed with polyvinyl alcohol powder and kept for $4 \mathrm{~h}$ at $5^{\circ} \mathrm{C}$ for equilibration. After equilibration, straws were kept in automatic programmable biological cell freezer (IMV Technology, France) until the temperature of straws reached $-140^{\circ} \mathrm{C}$. Then, straws were plunged into liquid nitrogen $\left(-196^{\circ} \mathrm{C}\right)$ for storage and stored for $24 \mathrm{~h}$ before thawing at $37^{\circ} \mathrm{C}$ for $30 \mathrm{~s}$. From each group, semen samples were evaluated for various seminal attributes (total motility, viability, acrosomal integrity, abnormality, and hypo-osmotic swelling response) at pre-freeze and post-thaw stage.

\section{Semen evaluation}

Seminal attributes

A drop of the diluted semen was kept on a clean, grease free, pre-warmed glass slide; cover slip was placed, and total motility was assessed under high power magnification (400×magnification) of a phase contrast microscope. Percentage of live and abnormal spermatozoa was determined by a differential staining technique using Eosin-Nigrosin stain [9]. Acrosomal intactness was determined by Giemsa stain as per method described by Watson [10]. Hypo-osmotic swelling test (HOST) was carried out according to the method described by Jeyendran et al. [11].

\section{Statistical analysis}

Data were statistically analyzed by one-way ANOVA and results were expressed as mean \pm standard error. Means were compared using Tukey's multiple comparisons test. The statistical package of GraphPad Prism, San Diego, USA was used for analyzing the data.

\section{Results and Discussion \\ Total motility}

The mean values of total motility are presented in Table-1. The total motility of a semen sample gives a good indication of fertility of the bull and ability of spermatozoa to withstand the stress of the cryopreservation process. After dilution, the percentage of total motility was $74.67 \pm 1.09,74.50 \pm 0.92,74.58 \pm 1.03$,

Table-1: Effect of egg yolk powder on seminal attributes and sperm function of buffalo semen at post-dilution, pre-freeze, and post-thaw stage.

\begin{tabular}{|c|c|c|c|c|c|}
\hline Seminal attributes & Stage & Group I & Group II & Group III & Group IV \\
\hline \multirow[t]{3}{*}{ Total motility } & PD & $74.67 \pm 1.09$ & $74.50 \pm 0.92$ & $74.58 \pm 1.03$ & $75.17 \pm 1.15$ \\
\hline & PF & $67.42 \pm 1.19^{\mathrm{B}}$ & $67.78 \pm 0.99^{\mathrm{B}}$ & $69.50 \pm 1.14^{\mathrm{A}}$ & $68.92 \pm 1.16^{\mathrm{A}}$ \\
\hline & PT & $48.17 \pm 0.71^{b}$ & $49.85 \pm 0.78^{b}$ & $54.58 \pm 0.65^{a}$ & $48.75 \pm 0.83^{b}$ \\
\hline \multirow[t]{3}{*}{ Viability } & PD & $76.25 \pm 1.07$ & $76.25 \pm 1.28$ & $77.17 \pm 1.22$ & $76.83 \pm 1.17$ \\
\hline & PF & $69.67 \pm 1.19^{\mathrm{B}}$ & $70.75 \pm 1.19^{A}$ & $71.08 \pm 1.31^{\mathrm{A}}$ & $70.17 \pm 1.22^{\mathrm{A}}$ \\
\hline & PT & $54.78 \pm 1.44^{b}$ & $55.34 \pm 0.75^{b}$ & $61.33 \pm 0.71^{a}$ & $54.25 \pm 1.00^{\mathrm{b}}$ \\
\hline \multirow[t]{3}{*}{ Acrosomal integrity } & PD & $78.58 \pm 1.01$ & $78.50 \pm 1.13$ & $78.83 \pm 1.15$ & $78.42 \pm 1.15$ \\
\hline & PF & $72.50 \pm 1.00$ & $72.75 \pm 1.21$ & $72.67 \pm 1.10$ & $72.83 \pm 1.01$ \\
\hline & PT & $57.69 \pm 0.88^{b}$ & $57.50 \pm 0.71^{b}$ & $65.67 \pm 0.54^{a}$ & $58.50 \pm 0.71^{b}$ \\
\hline \multirow[t]{3}{*}{ Abnormality } & PD & $10.33 \pm 0.47$ & $10.33 \pm 0.45$ & $9.83 \pm 0.41$ & $10.67 \pm 0.41$ \\
\hline & PF & $11.00 \pm 0.46$ & $10.75 \pm 0.41$ & $10.58 \pm 0.38$ & $11.17 \pm 0.46$ \\
\hline & PT & $11.25 \pm 0.45^{\mathrm{B}}$ & $11.25 \pm 0.48^{\mathrm{B}}$ & $10.78 \pm 0.40^{B}$ & $12.50 \pm 0.50^{\mathrm{A}}$ \\
\hline \multirow[t]{3}{*}{$\operatorname{HOS}(\%)$} & PD & $68.75 \pm 0.87$ & $69.83 \pm 0.74$ & $69.33 \pm 0.78$ & $69.75 \pm 0.81$ \\
\hline & PF & $61.08 \pm 0.81^{B}$ & $63.17 \pm 0.81^{A}$ & $62.67 \pm 0.69^{A}$ & $60.92 \pm 0.82^{B}$ \\
\hline & PT & $41.76 \pm 0.69^{\mathrm{B}}$ & $44.17 \pm 0.79^{A}$ & $45.50 \pm 0.94^{A}$ & $40.83 \pm 0.72^{B}$ \\
\hline
\end{tabular}

$\mathrm{PD}=$ Post-dilution, PF=Pre-freeze, PT=Post-thaw. Groups I, II, III, and IV contain $10 \%$ fresh egg yolk, 2\%, 4\%, and $6 \%$ egg yolk powder, respectively. Mean showing different superscripts in upper case letters ( $A$ and $B$ ) and lower case letters $(a$ and $b)$ in row differ significantly at $5 \%(p<0.05)$ and $1 \%(p<0.01)$, respectively 
and $75.17 \pm 1.15$ in Groups I, II, III, and IV, respectively. No significant difference in motility percentage at post-dilution was recorded among any groups. After dilution, the percentage of motile spermatozoa was higher than the values reported by Mittal et al. [12]. At pre-freeze stage, the percentage of motile spermatozoa was significantly $(p<0.05)$ higher in Groups III and IV as compared to Groups I and II. At pre-freeze stage, the percentage of motile spermatozoa was higher than the values reported by Rao et al. [13]. At post-thaw stage, percentage of individual motility was significantly $(p<0.01)$ higher in Group III as compared to other three groups. The percentage reduction in total motility was $35.48,33.08,26.18$, and 35.14 in Groups I, II, III, and IV, respectively.

\section{Viability}

Viability of spermatozoa in a semen sample is significantly and positively correlated with initial motility, post-thaw motility, and fertility of spermatozoa. Post-dilution viability was $76.25 \pm 1.07$, $76.25 \pm 1.28,77.17 \pm 1.22$, and $76.83 \pm 1.17$ in Groups I, II, III, and IV, respectively. The percentage of live spermatozoa was higher than the values reported by Bhakat et al. [14]. No significant differences in viability percentage were recorded among any groups post-dilution. At pre-freeze stage, percent viability was significantly $(p<0.05)$ higher in Groups II, III, and IV as compared to Group I. At post-thaw stage, percent viability was significantly $(p<0.01)$ higher in Group III as compared to Groups I, II, and IV. The percentage reduction in viability was $28.15,27.42,20.52$, and 29.61 in Groups I, II, III, and IV, respectively.

\section{Acrosomal integrity}

Acrosomal integrity of mammalian spermatozoa is prerequisite for capacitation, normal acrosome reaction, and successful fertilization in vivo. The percentage of intact acrosomes after dilution in Groups I, II, III, and IV was $78.58 \pm 1.01,78.50 \pm 1.13,78.83 \pm 1.15$, and $78.42 \pm 1.15$, respectively. The percentage of spermatozoa with intact acrosome was higher than the values reported by Meena et al. [15] and Patel and Siddiquee [16]. After dilution and pre-freeze stage, no significant difference in the percentage of acrosomal integrity was recorded among any groups. However, at post-thaw stage, the percentage of spermatozoa with intact acrosome was significantly $(p<0.01)$ higher in Group III as compared to other three groups. Values of acrosomal integrity in all groups were lower which can normally occur in buffalo semen and also observed by Singh et al. [8]. Percentage decline in acrosomal integrity was $26.58,26.75,16.69$, and 25.40 in Groups I, II, III, and IV, respectively.

\section{Abnormality}

After dilution, the percentage of abnormal spermatozoa in Groups I, II, III, and IV was $10.33 \pm 0.47$, $10.33 \pm 0.45,9.83 \pm 0.41$, and $10.67 \pm 0.41$, respectively. The percentage of abnormal spermatozoa was in agreement to the reports of Bhakat et al. [14]. No significant difference in the percentage of abnormal spermatozoa was recorded after dilution and at the pre-freeze stage. However, at post-thaw stage, the percentage of abnormal spermatozoa were significantly $(\mathrm{p}<0.05)$ higher in Group IV as compared to other three groups.

\section{HOST response}

The percentage of HOST positive spermatozoa after dilution in Groups I, II, III, and IV were $68.75 \pm 0.87,69.83 \pm 0.74,69.33 \pm 0.78$, and $69.75 \pm 0.81$, respectively. The HOST (\%) in our study was comparable to values of Meena et al. [15] but higher than the values reported by Bhakat et al. [14]. No significant difference in HOST response was recorded after dilution among any groups. However, at pre-freeze and post-thaw stage, the percentage of HOST positive spermatozoa were significantly $(p<0.05)$ higher in Groups II and III as compared to Groups I and IV. The percentage reduction in HOST response was 39.25, 36.76, 34.37, and 41.46 in Groups I, II, III, and IV, respectively.

\section{Conclusion}

Addition of egg yolk powder at 4\% level in the extender yielded significantly better results in terms post-thaw semen quality as compared to the fresh egg yolk and other levels of egg yolk powder ( $2 \%$ and $6 \%)$. Egg yolk powder at a level of $4 \%$ can be effectively used as an alternative to fresh egg yolk for cryopreservation of Murrah buffalo semen.

\section{Author's Contributions}

NK and SAL planned and carried out research work. JKP and SKG provided lab facility and necessary help during research work. MHJ helped in the statistical analysis of Data. All authors read and approved the final manuscript.

\section{Acknowledgments}

The authors are thankful to Director, Indian Veterinary Research Institute, Izatnagar- 243122, Bareilly, for providing facilities and fund during this research work.

\section{Competing Interests}

The authors declare that they have no competing interests.

\section{References}

1. Phillips, P.H. and Lardy, H.A. (1940) A yolk-buffer pabulum for preservation of bull sperm. J. Dairy Sci., 2: 399-404.

2. Salamon, S. and Maxwell, W.M.C. (1995) Frozen storage of ram semen I. Processing, freezing, thawing and fertility after cervical insemination (review). Anim. Reprod. Sci., 37: $185-249$.

3. Andrabi, S.M.H., Ansari, M.S., Ullah, N., Anwar, M., Mehmood, A. and Akhter, S. (2008) Duck egg yolk in extender improves the freezability of buffalo bull spermatozoa. Anim. Reprod. Sci., 104: 427-433.

4. Gil, J., Lundeheim, N., Soderquist, L. and Rodri'guezMartı'nez, H. (2003) Influence of extender, temperature, and addition of glycerol on post-thaw sperm parameters in ram semen. Theriogenology, 59: 1241-1255. 
5. OIE. (2003) Terrestrial Animal Health Code. Appendix 3.2.1, Article 3.2.2.4. Available from: http://www.oie. int/eng/normes/Mcode/A_summry.htm. Accessed on 21-07-2014

6. Marco-Jiménez, F., Puchades, S., Mocé, E., Viudes-deCartro, M.P., Vicente, J.S. and Rodriguez, M. (2004) Use of powdered egg yolk vs fresh egg yolk for the cryopreservation of ovine semen. Reprod. Domest. Anim., 39: 438-441.

7. Ansari, M.S., Rakha, B.A., Andrabi, S.M.H. and Akhter, S. (2010) Usefulness of powdered and fresh egg yolk for cryopreservation of Zebu bull spermatozoa. Reprod. Biol., 10(3): 235-240.

8. Singh, M., Barik, N.C., Ghosh, S.K., Prasad, J.K., Rajoriya, J.S., Soni, Y.K., Kumar, A., Chaudhary, J.K. and Srivastava, N. (2015) Egg yolk powder an alternative to fresh egg yolk for buffalo semen cryopreservation. Indian J. Anim. Sci., 85(1): 40-42.

9. Campbell, R.G., Hancock, J.L. and Rothschild, L. (1953) Counting live and dead bull spermatozoa. J. Exp. Biol., 30: 44-45.

10. Watson, P.F. (1975) Use of Giemsa stain to detect changes in the acrosome of frozen ram spermatozoa. Vet. Rec., 97: 12-15.

11. Jeyendran, R.S., Vander Ven, H.H., Parez-pelaez, M.,
Crabo, B.G. and Zaneweld, L.J.D. (1984) Development of an assay to assess the functional integrity of the human membrane and its relationship to other semen characteristics. J. Reprod. Infertil., 70: 219-228.

12. Mittal, P.K., Anand, M., Madan, A.K., Yadav, S. and Kumar, J (2014) Antioxidative capacity of vitamin E, vitamin $\mathrm{C}$ and their combination in cryopreserved Bhadavari bull semen. Vet. World, 7(12): 1127-1131.

13. Rao, T.K.S., Kumar, N., Patel, N.B., Chauhan, I. and Chaurasia, S. (2013) Sperm selection techniques and antioxidant fortification in low grade semen of bulls: Review. Vet. World, 6(8): 579-585.

14. Bhakat, M., Mohanty, T.K., Singh, S., Gupta, A.K., Chakravarty, A.K. and Singh, P. (2015) Influence of semen collector on semen characteristics of Murrah buffalo and crossbred bulls. Adv. Anim. Vet. Sci., 3: 253-258.

15. Meena, G.S., Raina, V.S., Gupta, A.K., Mohanty, T.K., Bhakat, M., Abdullah, M. and Bishist, R. (2015) Effect of preputial washing on bacterial load and preservability of semen in Murrah buffalo bulls. Vet. World, 8(6): 798-803.

16. Patel, B.R. and Siddiquee, G.M. (2013) Physical and morphological characteristics of Kankrej bull semen. Vet. World, 6(7): 405-408. 